\title{
Color Comprehension And Color Categories Among Blind Students: A Multi-Sensory Approach In Implementing Concrete Language To Include All Students In Advanced Writing Classes
}

Salinee Antarasena, Ramkhamhaeng University, Bangkok, Thailand

\begin{abstract}
This study investigates teaching methods regarding color comprehension and color categorization among blind students, as compared to their non-blind peers and whether they understand and represent the same color comprehension and color categories. Then after digit codes for color comprehension teaching and assistive technology for the blind had been implemented to replace the traditional way of teachings, their color comprehension was re-investigated through color categories test, examining their ability in distinguishing between shades of similar colors and expressing correct color naming that is relevant to given contexts. Further discussion from the study also reveals how this understanding of color comprehension and color categories can help modify print materials which would allow blind students, students with low vision, as well as those with color blindness to be exposed to all the components of language and literacy-related activities as they wish, and how the teachers can make use of this color comprehension and color categories to integrate a multi-sensory approach to benefit all students, not just those with special needs.
\end{abstract}

\section{INTRODUCTION}

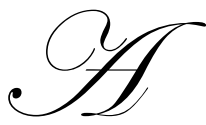

ccording to National Statistics (2003), the latest number of students with disabilities enrolled in tertiary education in 2006 was 1,452 in total (Table 1); more than half of which have been reported with significant visual impairment, hearing impairment and limb disability.

Table 1: Numbers of Students with Special Needs Studying at Tertiary Level in 2006 Displayed by Types of Disabilities

\begin{tabular}{|l|c|c|c|}
\hline \multicolumn{1}{|c|}{ Types of Disabilities } & \multicolumn{2}{c|}{ Gender } & \multirow{2}{*}{ Total } \\
\cline { 2 - 4 } & Male & Female & \\
\hline 1. Limb Disability & 181 & 180 & 361 \\
\hline 2. Hearing Impairment & 149 & 156 & 305 \\
\hline 3. Visual Impairment & 162 & 114 & 276 \\
\hline 4. Autism & 192 & 39 & 231 \\
\hline 5. Attention Deficit & 150 & 3 & 153 \\
\hline 6. Intellectual Disability & 37 & 22 & 59 \\
\hline 7. Learning Disability & 23 & 12 & 35 \\
\hline 8. Multiple Disabilities & 13 & \multicolumn{2}{c|}{8} \\
\hline 9. Speech and Language Impairment & 4 & \multicolumn{2}{c|}{7} \\
\hline Total & 911 & 541 & 1,452 \\
\hline
\end{tabular}

Source: Commission on Higher Education, 2007 
However, for students with disabilities enrolled at Ramkhamhaeng University in particular, the Students Affair Division reported that students with visual impairment were the highest percentages among students with other disabilities (Table 2).

Table 2: Numbers of Students with Sight Problems Studying at Ramkhamhaeng University in 2007 Displayed by Types of Disabilities

\begin{tabular}{|l|c|c|c|}
\hline \multicolumn{1}{|c|}{ Types of Disabilities } & \multicolumn{2}{c|}{ Gender } & \multirow{2}{*}{ Total } \\
\cline { 2 - 4 } & Male & 17 & 65 \\
\hline 1. Visual Impairment & 48 & 25 & 44 \\
\hline 2. Limb Disability & 19 & - & 2 \\
\hline 3. Hearing Impairment & 2 & 1 & 1 \\
\hline 4. Intellectual Disability & - & 43 & 112 \\
\hline Total & 69 & \multicolumn{2}{c}{} \\
\hline
\end{tabular}

Source: Students Affair Division, 2007

Although with learning supports provided by the university through Students Affair Division, blind students often found the use of standard educational materials a daily struggle to fit in with their unique physical characteristics in doing basic readings and writings that are essential for their language development. Oftentimes, the print materials used for in-class lectures have been made accessible to students who are blind or have low vision through alternate formats, including audiocassettes, Braille, e-Documents (e-Learning), and Large Print while others with more limited budget are left with traditional learning tools as regular students.

Blind students, therefore, have become more prone to enroll in courses that they can rely on the use of assistive devices that are available to them; and after completing four basic compulsory English language courses at the university, it is safe for them to assume that other advanced courses, which stress the integration of practices into the course assessment, would be fairly frustrating experiences.

Creative writing class, for example, is an English writing course that emphasizes heavily on expressive and writing skills and which requires the students to describe their interactions with the world through concrete images. With such definition, there is a greater need among the Blind to communicate their observation precisely and to replace generalization with the use of concrete, sensory details. This is most challenging when blind students need to engage in language associated with the use of five senses to craft their own writing. Often, people in general falsely believe that the art and art of writing is primarily a result of visual appreciation and that it is of no interest to people who have vision problems or vision loss.

This research then first seeks to examine whether blind students understand and represent color concepts that we non-blind people commonly perceive and how they categorize and remember "colors".

\section{OBJECTIVES}

Prior studies on color categorization have accounted for the study's start in several ways. First, it might be the case that all humans (including blind people) have a universal set of cognitive categories that may be innately determined and independent of the terms used to describe them. Second, colors - other than basic, may be subject to a culture-specific naming system; but after implementing perceptual matching judgments for color through criteria set by color codes, any such colors may be judged more correctly with digits rather than with different names.

This study, therefore, aims to investigate the language learning toward color comprehension and color categorization among blind students, as compared to their regular peers, when color categorizations are taught, measured and verified through a digit system rather than through a visual system - whether blind students can grasp identical or similar criteria of color sets as those of their peers. 
Key research questions include:

- Do blind students understand and represent color comprehension and color categories like non-blind people?

- If blind students can understand and represent color categories like non-blind people, can they distinguish between shades of similar colors?

- Have blind students acquired the same color categories and color naming as non-blind students before the correct acquisition of the linguistic terms?

- If the criteria for color naming has been put into digit codes, will that help blind students progress color comprehension or better help them distinguish shades of similar colors and express the correct shade when required?

- $\quad$ How can the understanding of color comprehension and color categories help modify print materials to meet the needs of blind students for advanced English courses?

- How can teachers make use of color comprehension and color categories to integrate a multi-sensory approach to benefit all students, not just those with special needs?

\section{LITERATURE REVIEW}

Researches and studies done by Berlin and Kay (1969), Shepard (1997), Kaiser and Boynton (1996), Lucy (1997), and Boynton (1997) investigated how languages categorize colors and data from color naming studies also suggested that strong universal tendencies in color naming exist across languages. It was first put forward by Berlin and Kay (1969) that there is a particular set of basic color categories shared between all humans. These basic categories (named in English as red, green, blue, yellow, black, white, grey, pink, orange, purple and brown) are considered distinct from other terms (for example, turquoise or maroon) because such basic colors are known to all members of a community and generally named with mono-lexemic words.

However, more recent studies on color categorization across languages have shown that there is a growing body of evidence which found consistent differences in perceptual and memory tasks regarding color categorization and that there are languages that appear not to fit the proposed universal pattern, giving the idea that similarities in color naming may be limited in cross-linguistic scope as most such languages do not have separate color terms but rather use a single term to cover these regions of color space (Rosch, 1972; Kay and Regier, 2003), and some proposed color terms that disagree with comparable boundaries in English (Roberson, 2000; Davidoff, 1999). A number of such studies (Kay \& Kempton, 1984; Pilling, Wiggett, Ozgen, \& Davies, 2003; and Roberson \& Davidoff, 2000; Roberson, Davies and Davidoff, 2000) also reported substantial differences in perceptual judgments and memory performance between languages with basic color terms and that the primary colors of red, blue, green and yellow are learned first (Adelson, 2005).

One of the most recognized studies by Roberson and her colleagues (2005) found that speakers of the two given languages encode, remember and discriminate color stimuli in different ways. English, for example, has 11 such terms, the same as in many of the world's major languages, and Himba has five, each of which covers a broader range of colors. As another example, Himba children come to use one word, "zoozu," to embrace a variety of dark colors that English speakers would call dark blue, dark green, dark brown, dark purple, dark red or black. Other studies (Bornstein, Kessn \& Weiskopf, 1976; and Franklin \& Davies, 2004) argue that all humans may be born with a universal set of cognitive categories that are later distorted by learning the appropriate set of categories for their language.

Based on the studies regarding relationships between color categorization, linguistic, and perceptual phenomena, it is thus safe to assume that although various studies have shown that there are certain 'basic colors' shared by all humans, there is a wide variation in how humans describe where the boundaries between colors lie ('in-betweens'), thus giving different names to discriminate between various colors. In this study, initial expressive skills toward color comprehension and color categorization among blind students were first assessed and then reinvestigated after a new way of color concept acquisition had been introduced. 


\section{DEFINITIONS}

Participants with blindness included in this study were reported to have the following characteristics:

- $\quad$ Officially registered according to the Rehabilitation for Disabled Person Act, B.E. 2534 (1991) ${ }^{1}$. According to the description stated in the Rehabilitation of Disabled Persons Act B.E. 2534, impairment of vision means "the better eye, after using regular eyeglasses, is able to see less than $6 / 18$ or 20/70 downward until unable to see any light, or a visual field of less than 30 degrees.

- $\quad$ No records of multiple disabilities

\section{METHODOLOGY}

A pilot study initially tracked color comprehension and color categories among two populations: participants with and without vision loss.

\section{Participants}

Of the 65 blind participants, 12 blind students with the following characteristics were included in the test:

- $\quad$ Reported of having two-eyed blindness at birth (birth defect)

- $\quad$ Already completed at least two out of four basic compulsory English language courses, including EN 101 (Basic Sentences and Essential Vocabulary in Daily Life), EN 102 (Sentences and Vocabulary in General Use), EN 201 (Reading for Comprehension) and EN 202 (Interpretative Reading)

- $\quad$ Able to write or type both in English and Thai by themselves

- $\quad$ PC literate with access to internet and email

The same number of non-blind participants (12) was selected, all with the following characteristics:

- $\quad$ Already completed at least two out of four basic compulsory English language courses, including EN 101 (Basic Sentences and Essential Vocabulary in Daily Life), EN 102 (Sentences and Vocabulary in General Use), EN 201 (Reading for Comprehension) and EN 202 (Interpretative Reading)

- $\quad$ Able to write or type both in English and Thai by themselves

- $\quad$ PC literate with access to internet and email

\section{Materials}

Questions regarding color categories were divided into two parts:

1) The first part was to establish initial understanding of color comprehension and color categorization across both groups before the correct acquisition of the linguistic terms would have been implemented.

2) The second part was to examine the acquisition of color categories among the blind students group after the color digit codes teaching as to whether they would appropriately label colors and acquire appropriate set of color categories when specified.

\section{THE STUDY}

At the study's start, no participants received color teaching. Three of 12 blind students were later selected to proceed to the second part of the testing and to complete further color tests.

\footnotetext{
${ }^{1}$ JICA, "Country Profile on Disability (Kingdom of Thailand)", 2002, October 1, 2007

<siteresources.worldbank.org/DISABILITY/Resources/Regions/East-Asia-Pacific/JICA_Thailand.1.pdf〉.
} 


\section{First Testing: Color Comprehension and Categories}

The first study assigned all participants to complete both color comprehension tasks designed to access their understandings of basic and chromatic color (or multiple basic color) categories. Questions were sub-divided as follows:

- $\quad$ The first part covered basic colors (Red, Yellow, and Blue).

- $\quad$ The second part covered chromatic mixed colors (Green, Brown, White, Black, Olive Green and Indigo).

\section{RESULTS}

All participants, including 12 blind students, passed the combined naming and comprehension tasks in the first testing. Detailed results indicated similarity between color comprehensions across both groups (Tables 3 through 5).

Results indicated that participants showed no difference in accuracy of color categorizations across both tasks $(\mathrm{t}=-0.416, \mathrm{p}$-value $=.6812)$. In addition, both groups of participants were quick to identify examples for colors in the first tasks and their ability to identify the same examples to represent such colors was also obvious.

This result supported prior studies suggesting that primary colors are learned first - including individuals who were born blind - and that all humans might have been born with a universal set of cognitive categories that enables them to address the same or nearly the same color terms when named with mono-lexemic words.

Additionally, as participants (especially the blind) were reported to have slow response toward chromatic mixed colors, such as Olive Green and Indigo, this might suggest that their perceptual judgment toward detailed mapping of color categories (colors other than basic colors) - which might have been later set out by their learning of color categories of that language - might have assimilated their existing hue-based universal categories into a new set of spoken and written linguistic categories, something that is very limited to the blind participants.

Table 3: Results of Color Comprehension Task 1 (Basic Colors) of Both Groups

\begin{tabular}{|c|c|c|}
\hline Color & Objects & Frequency \\
\hline Red & Blood & 6 \\
& Strawberry & 2 \\
& Rose & 1 \\
& Sun & 1 \\
& THB 100 Bank note & 1 \\
& Heat & 1 \\
\hline Yellow & & \\
& Sunlight & 4 \\
& Golden Jubilee & 3 \\
& Celebration shirt & 2 \\
& Monk robe & 1 \\
& Ripen fruit & 1 \\
& Mango & 1 \\
\hline Blue & Banana & 3 \\
& Color in Thai flag & 2 \\
& Sea & 2 \\
& Sky & 1 \\
& Sky train & 1 \\
& My shirt & 1 \\
& Student sport shirt & 1 \\
& Guard uniform & 1 \\
& Plastic board &
\end{tabular}

Results taken by blind participants

\begin{tabular}{|c|c|c|}
\hline Color & Objects & Frequency \\
\hline Red & Rose & 3 \\
& Sun & 2 \\
& Blood & 1 \\
& Cherry & 1 \\
& Tomato & 1 \\
& Heart & 1 \\
& Apple & 1 \\
& Hong-Bao & 1 \\
& Red Chilli & 1 \\
\hline Yellow & Golden Jubilee & 5 \\
& Celebration shirt & 3 \\
& Banana & 2 \\
& Sunflower & 1 \\
& Monk robe & 1 \\
\hline Blue & Butter & 4 \\
& Sea & 8 \\
& Sky & \\
\hline
\end{tabular}

Results taken by non-blind participants 
Table 4: Results of Color Comprehension Task 2 (Chromatic Mixed Colors) of Both Groups

\begin{tabular}{|c|c|c|}
\hline Color & Objects & Frequency \\
\hline \multirow[t]{3}{*}{ Green } & Leaf & 6 \\
\hline & Tree & 5 \\
\hline & Lawn & 1 \\
\hline \multirow[t]{6}{*}{ Brown } & Soil & 3 \\
\hline & Dog & 2 \\
\hline & Dried leaf & 2 \\
\hline & Tree branch & 2 \\
\hline & Wooden desk & 1 \\
\hline & \begin{tabular}{|l} 
No answer \\
\end{tabular} & 2 \\
\hline \multirow[t]{8}{*}{ White } & $\begin{array}{c}\text { White cloth of a nun, bridal cloth, student uniform } \\
\text { Paper }\end{array}$ & 4 \\
\hline & Color in Thai flag & 2 \\
\hline & Cream & 1 \\
\hline & Cloud & 1 \\
\hline & Cement & 1 \\
\hline & No answer & 1 \\
\hline & Vague answer & 1 \\
\hline & & 1 \\
\hline \multirow[t]{7}{*}{ Black } & Night sky & 4 \\
\hline & Funeral cloth & 3 \\
\hline & Ink & 1 \\
\hline & Pepsi & 1 \\
\hline & Pencil & 1 \\
\hline & Hair & 1 \\
\hline & No answer & 1 \\
\hline \multirow[t]{5}{*}{ Olive Green } & Soldier uniform & 4 \\
\hline & Preserved egg & 2 \\
\hline & Mountain & 1 \\
\hline & No answer & 3 \\
\hline & Vague answer & 2 \\
\hline \multirow[t]{4}{*}{ Indigo } & Student uniform & 6 \\
\hline & Government Official uniform & 3 \\
\hline & Navy uniform & 1 \\
\hline & My trousers at work & 2 \\
\hline
\end{tabular}

Results taken by blind participants

\begin{tabular}{|c|c|c|}
\hline Color & Objects & Frequency \\
\hline Green & Tree & 8 \\
& Leaf & 1 \\
& Forest & 1 \\
& Vegetable & 1 \\
\hline Brown & Worm & 6 \\
& Soil & 2 \\
\hline White & Brown sugar & 1 \\
& Tree trunk & 1 \\
& Wood & 1 \\
& Dried grass & 1 \\
& Vague answer & 3 \\
& Paper & 2 \\
& White cloth of a nun & 2 \\
& Milk & 1 \\
& Cloud & 1 \\
& Jasmine flower & 1 \\
\hline
\end{tabular}


Table 4: Continued

\begin{tabular}{|c|c|c|}
\hline Color & Objects & Frequency \\
\hline Black & Night sky & 7 \\
& Ink & 1 \\
& Outer space & 1 \\
& Dark room (photo lab) & 1 \\
& Dirty canal & 1 \\
\hline Olive Green & Vague answer & $\mathbf{1}$ \\
& Soldier uniform & 3 \\
& Preserved egg & 1 \\
& Moss & $\mathbf{1}$ \\
& No answer & $\mathbf{1}$ \\
\hline Indigo & Vague answer & 4 \\
& Navy uniform & 2 \\
\hline
\end{tabular}

Results taken by non-blind participants

Table 5: Combined Scores of Color Comprehension - (Tasks 1 \& 2) Across Both Groups

\begin{tabular}{|c|c|c|c|}
\hline Participants & $\begin{array}{c}\text { Basic colors } \\
\text { (3) }\end{array}$ & Chromatic mixed colors (6) & $\begin{array}{c}\text { Total } \\
\text { (9) }\end{array}$ \\
\hline 1 & 3 & 6 & 9 \\
\hline 2 & 3 & 4 & 7 \\
\hline 3 & 3 & 6 & 9 \\
\hline 4 & 3 & 6 & 6 \\
\hline 5 & 3 & 3 & 7 \\
\hline 6 & 3 & 4 & 7 \\
\hline 7 & 3 & 5 & 9 \\
\hline 8 & 3 & 4 & 9 \\
\hline 10 & 3 & 6 & 9 \\
\hline 11 & 3 & 5 & 9 \\
\hline
\end{tabular}

Results taken by blind participants

\begin{tabular}{|c|c|c|c|}
\hline Participants & $\begin{array}{c}\text { Basic colors } \\
(3)\end{array}$ & Chromatic mixed colors (6) & $\begin{array}{c}\text { Total } \\
(9)\end{array}$ \\
\hline 1 & 3 & 6 & 9 \\
\hline 2 & 3 & 4 & 7 \\
\hline 3 & 3 & 6 & 7 \\
\hline 4 & 3 & 4 & 8 \\
\hline 5 & 3 & 5 & 9 \\
\hline 6 & 3 & 6 & 9 \\
\hline 7 & 3 & 5 & 9 \\
\hline 8 & 3 & 6 & 9 \\
\hline 9 & 3 & 6 & 9 \\
\hline 10 & 3 & 6 & 9 \\
\hline 11 & 3 & 4 & 9 \\
\hline
\end{tabular}

Results taken by non-blind participants 


\section{Follow-Up Study: Color Codes and Color Categorization}

Three of the 12 blind participants who are proficient in using two assistive softwares, JAWS for Window (JFW) and PPA Tatip, were presented with fundamentals of HTML color codes and a large database of web-based color naming. The basic hue colors were further subdivided based on the codes and explanations for detailed mapping of color boundaries. A color wheel was also put through their fingers by tactile methods.

\section{Fundamental Rules for Color Wheel and Color Mixing}

With tactile methods, the blind participants studied the relationships between the colors. Figure 1 below shows a color wheel comprising of three primary colors (Red, Yellow and Blue), three secondary colors (Green, Orange, and Violet) and six tertiary colors (Red-orange, Red-violet, Yellow-Green, Yellow-Orange, Blue-Green and Blue-Violet), all of which have been taught in class.

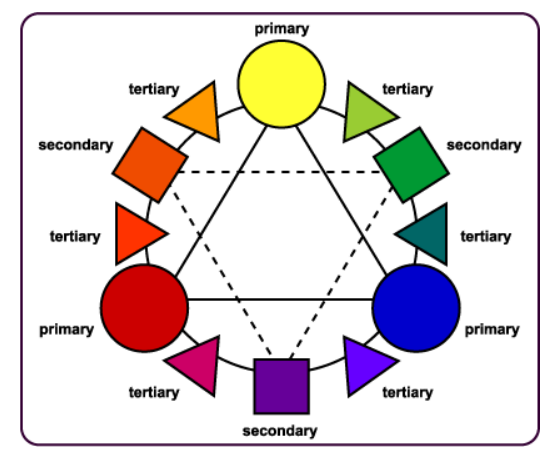

Figure 1: Color Wheel Taught in Class

Then, students were introduced more color concepts through HTML color codes, (sometimes called web colors or colors normally used in designing web pages), as well as methods for describing and specifying shades of similar colors.

\section{HTML Color Codes}

In order to give blind participants an alternative way to specify colors they need, color boundaries were then introduced in an RGB triplet form, or in hexadecimal format (a hex triplet), and later matched with their common English and Thai names.

The hex triplet is formed by concatenating three integers in hexadecimal notation in the following order:

- $\quad$ First pair: red value

- $\quad$ Second pair: green value

- $\quad$ Third pair: blue value

Basically, as hexadecimal codes define color property through that RGB codes - one for each of three primary colors (red, green, blue) - changes to one or more of the these three integers will alter the color. Color category boundaries were then taught respectively in such hexadecimal notation along with their matching English and Thai common color names. After a three-hour session with JFW and PPA Tatip, blind participants were allowed time to play around hexadecimal codes by themselves (Figures 2 through 4 ). 


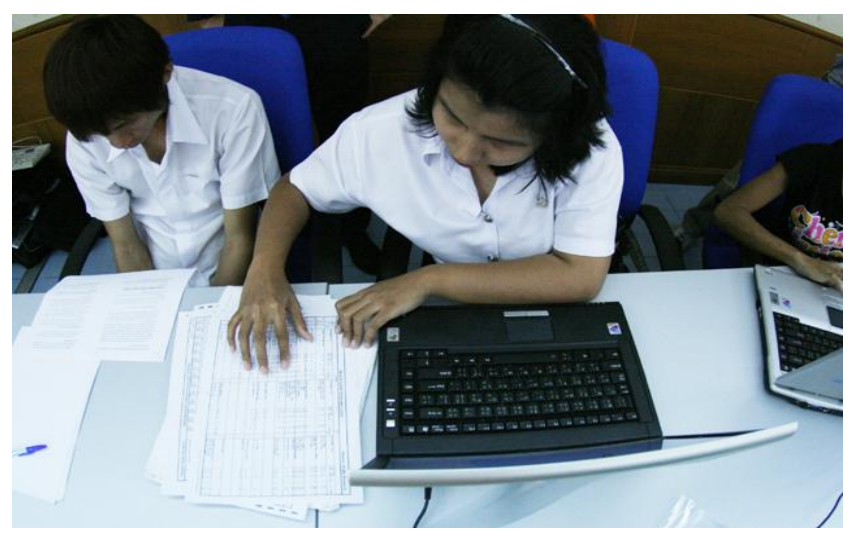

Figure 2: Student Checking Her Lecture Notes in Braille

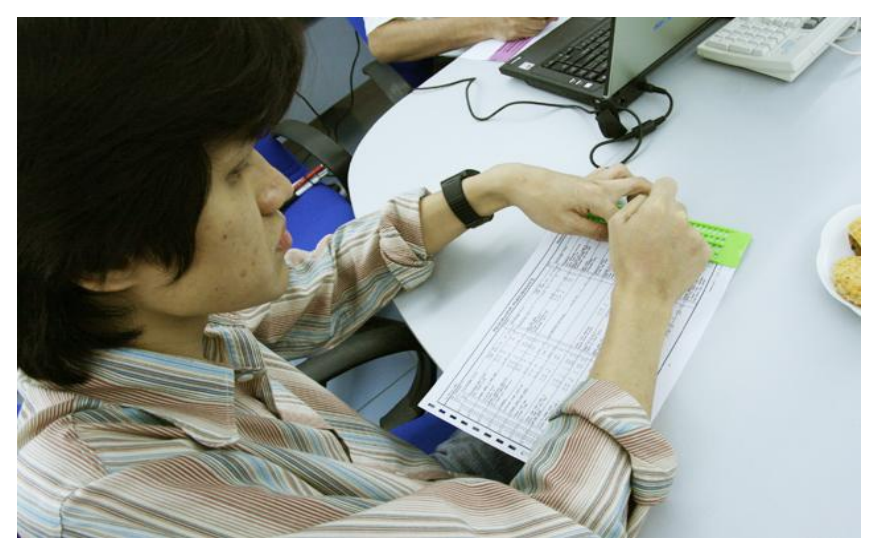

Figure 3: Student Reviewing His Lecture Notes After the Session

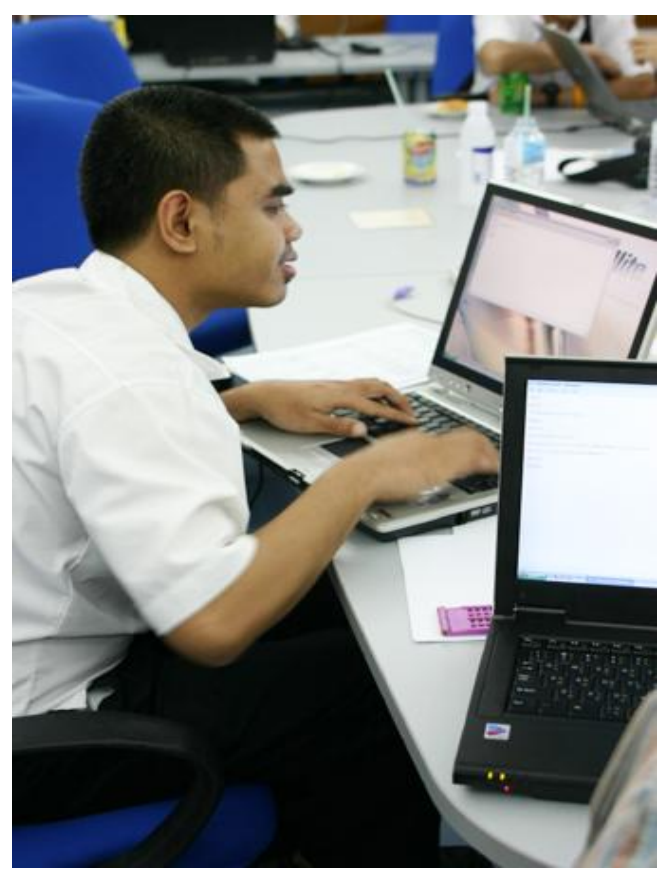

Figure 4: Student Using JFW and PPA Tatip 
As initial understanding of colors is considered important for crafting concrete language of their own, after an hour lunch break, their ability in color comprehension and color naming was accessed through a practice trial in which all of them were given common color names - first for basic colors, then secondary and tertiary colors - one at a time and in random order, before giving them five minutes for each to verify hex color codes that match with the names.

These questions were to address color response among the blind participants in earlier pilot studies: 1) whether they really have existing perceptual judgments toward color categories like non-blind participants or they only memorize and set out a presumed set of examples for those colors and 2) whether their errors (vague and no answers) in prior studies were results of their limited language or stock of words. Results of this trial are shown in Table 6.

Table 6: Results of Color Match Taken by Blind Students

\begin{tabular}{|l|c|c|c|}
\hline \multicolumn{1}{|c|}{ Test } & Student 1 & Student 2 & Student 3 \\
\hline $\begin{array}{l}\text { PART 1 (3) } \\
\text { Basic colors }\end{array}$ & 3 & 3 & 3 \\
\hline $\begin{array}{l}\text { PART 2 (3) } \\
\text { Secondary colors }\end{array}$ & 2 & 2 & 1 \\
\hline $\begin{array}{l}\text { PART 3 (6) } \\
\text { Tertiary colors }\end{array}$ & 3 & 1 & 4 \\
\hline Total & $\mathbf{8}$ & $\mathbf{6}$ & $\mathbf{8}$ \\
\hline
\end{tabular}

Results revealed that their uses of hex color codes were $100 \%$ accurate for basic colors, $55.6 \%$ accurate for secondary and $44.4 \%$ accurate for tertiary colors, respectively. This coincides with results taken previously in pilot studies and reconfirms that these blind students have acquired correct color categories toward basic colors; but when detailed mapping of color categorization is required, they might have found some difficulties in determining specific colors across color boundaries. It is therefore safe to assume that blind students might either have established some perceptual judgments toward basic color categories like non-blind participants, but for chromatic colors, they may or may not have established perceptual judgments prior to the study, but might have only memorized a presumed set of examples for those colors.

Although these students already acquired initial color comprehension and categorization toward a number of colors, it appears that their inability to identify some specific colors might have resulted from their limited language, as most of them did not learn at an early age many words which name or associate with colors. Therefore, increasing their stock of words is of further concern as these students need to store an adequate number of words before moving on to the next step - the concrete descriptions in their writings, which is the requirement of the writing course at the tertiary level.

The students were then explained the chromatic colors through changes of three integers in hex triplet codes, along with common color names; and in order to ensure their ability in specifying colors, they were asked to complete the following three tasks in 30 minutes.

The test covers both basic and chromatic color categories as follows:

1) 1-8 Multiple-choice, each showing similar shades of a color and asking participants to find the correct shade through hex color codes that match with the specified color in the context (each with six choices)

2) 9-15 Fill-in, each asking participants to fill in correct colors through hex color codes that match with the given context

3) 16-20 Fill-in, each asking participants to interpret color codes and fill in matching color labels of such colors 


\section{Results}

Table 7.

All participants passed the test with total scores of 14,15 and 16 (out of 20). The results are shown in

Table 7: Results of Color Comprehension Test Taken by Blind Students

\begin{tabular}{|c|c|c|c|}
\hline Test & Student 1 & Student 2 & Student 3 \\
\hline $\begin{array}{l}\text { PART 1 (8) } \\
\text { Identifying similar shades of color }\end{array}$ & 8 & 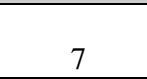 & 8 \\
\hline $\begin{array}{l}\text { PART 2 (7) } \\
\text { Fill-in appropriate colors } \\
\text { according to given context }\end{array}$ & 5 & 4 & 6 \\
\hline $\begin{array}{l}\text { PART } 3 \text { (5) } \\
\text { Fill in appropriate common names } \\
\text { according to color codes }\end{array}$ & 1 & 4 & 2 \\
\hline Total & 14 & 15 & 16 \\
\hline
\end{tabular}

According to the follow-up study, it is safe to assume that with hex color codes, participants demonstrated progress in color comprehension and color categories since at this stage, they could differentiate similar shades of color and identify correct shade of color in the given context (Parts 1 and 2). However, results in an earlier practice trial repeated that they were still reluctant to label colors in common color names and the scores of their color naming (Part 3) were significantly contrast with those of color comprehension in favor of hex color codes. In short, their accuracy in color categorization will decrease when color naming tends to be longer to fit in with the given context as their accuracy from Parts 1 through 3 varies from at 95.8\%, 71.43\%, and 46.67\%, respectively. This might suggest that their limited knowledge of color naming is still evident and they need further assistance in asserting more stocks of words.

\section{IMPLEMENTING MATERIALS FOR ALL}

Using Furigana (a Japanese reading aid which consists of smaller kana printed next to a kanji to indicate its pronunciation) during the lesson, the hex color codes were then placed above the line of the given context next to the specified colors, especially when it was necessary to distinguish between similar shades of colors. Figures 5 through 7 show a small writing session in an inclusive classroom using multi-sensory approach to meet the needs of all students during the course.

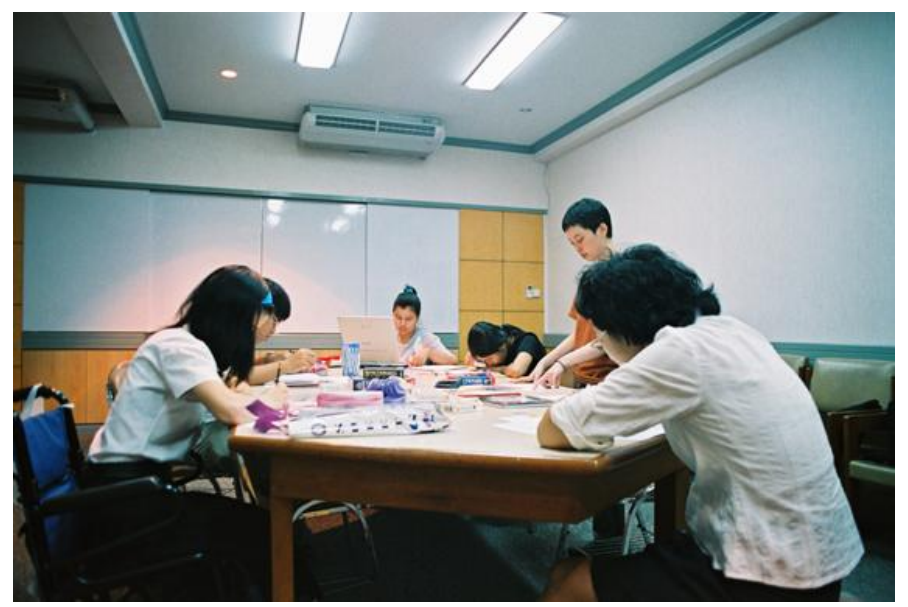

Figure 5: A Small Writing Session in Inclusive Classroom Using Multi-sensory Approach 


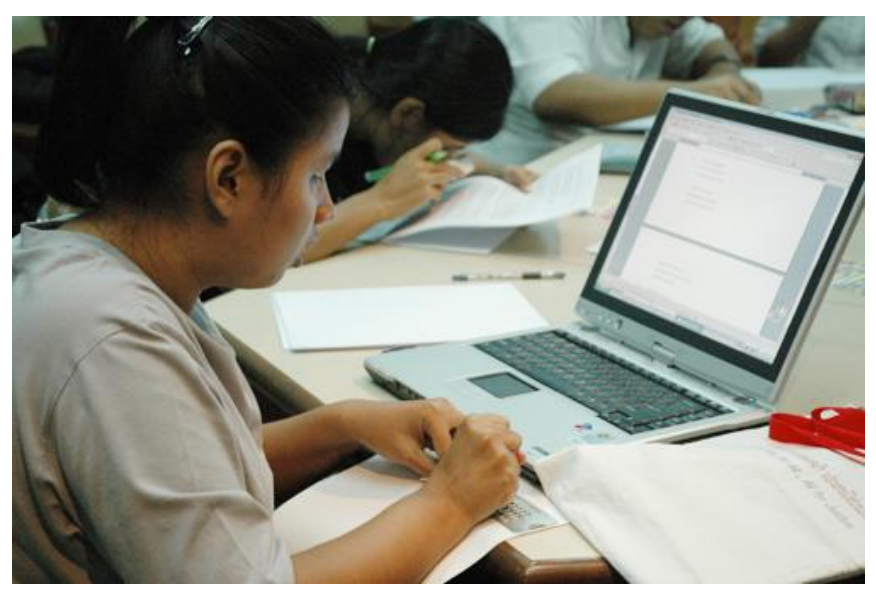

Figure 6: Blind Student Using her JFW and PPA Tatip to Craft Concrete Language

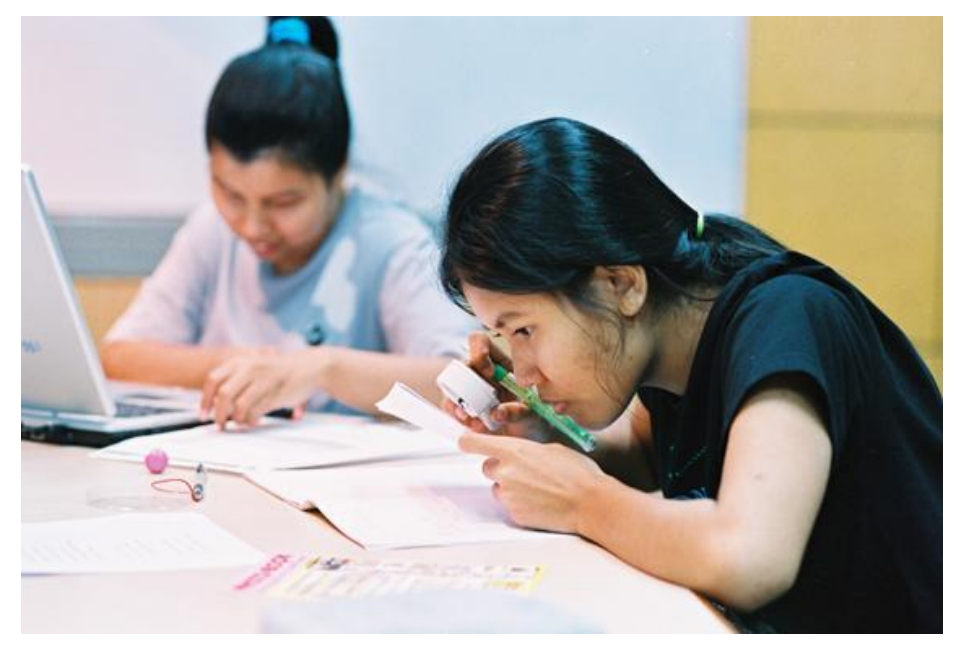

Figure 7: Student with Low-Vision Using Her Magnifier to Re-read Her Lectures

\section{CONCLUSION}

All students need the opportunity to be active participants in studying the subjects they need. There are multitudes of methods for creating materials that allow them to be exposed to all the components of language and literacy-related activities that can be utilized when developing no tech, low tech, and even some high tech adaptations. Teaching perceptual judgments toward color comprehension and color categorization through hex color codes is a way to craft learning materials created for a multi-sensory approach that can include all students to get involved in class activities and lessons. Small hints through hex color codes, attached with color description or color common names, may not be very convenient for non-blind students in general. However, it allows blind students synchronization of text to appreciate the same - or nearly the same - level of color appreciation as their non-blind peers and to reflect such color comprehension in language development and in crafting concrete description on their own. This can also benefit visual learners alike, especially those who are not familiar with chromatic mixed color names. In short, this multi-sensory approach to colors allows anyone to retain more information when detailed mapping of color categories is of significance. 


\section{AUTHOR INFORMATION}

Dr. Salinee Antarasena, Lecturer, Department of English and Linguistics. Faculty of Humanities, Ramkhamhaeng University, Bangkok, Bangkok, Thailand. Salinee Antarasena holds MA and Ph.D. both in Creative Writing from Macquarie University, Sydney. Her research interests focus on task-based learning and teaching, as well as innovative technology for special needs. As she won a Thai Government Scholarship in 2000, she decided to become a lecturer for the Department of English and Linguistics at Ramkhamhaeng University, where there are a large number of students with special needs as well as assistive equipments. To bring these students into the world of technology, she holds training program for students with special needs from time to time with assistance from qualified academic trainers in her country. Apart from this, she also conducts the research with the doctors, and teaches Medical English for the residents, and English for Healthcare Professionals for nurses at Rajvithi Hospital, Bangkok. In cooperation with the hospital, the main field of her previous research thus reports a monitoring educational program of children with special needs including those with hearing loss, vision loss, and learning disabilities (autism) and the evaluation of their learning progress. She recently has her Creative Writing books published this year for EFL students.

\section{REFERENCES}

1. Berlin, B. \& Kay, P. (1969). Basic Color Terms: Their Universality and Evolution. Berkeley: University of California Press.

2. Boroditsky, L. (2001). Does Language Shape Thought?: Mandarin and English Speakers' Conceptions of Time. Cognitive Psychology, 43: 1-22.

3. Dedrick, D. (1996). Color language universality and evolution. Philosophical Psychology, 9: 497-524.

4. Fitz-Gibbon, Carol T, and Morris, Lynn L (1987). How to Analyze Data. Los Angeles: SAGE Publications, Inc.

5. Gennari, S. et al. (2002). Motion events in language and cognition. Cognition, 83: 49-79.

6. Goldstone, R. L. (1994). Influences of categorization on perceptual discrimination. Journal of Experimental Psychology: General, 123: 178-200.

7. Guest. S. \& D. L. Van Laar (2000). "The structure of Colour Naming Space”. Vision Research, 40: 723734.

8. Guest. S. \& D. L. Van Laar (2002). "The Effects of Name Category and Discriminality on the Search Characteristics of Colour Sets". Perception, 31: 445-461.

9. Hardin, C.L. (1993). Color for Philosophers: Unweaving the Rainbow. Indianapolis: Hackett Publishing Company.

10. Heider, E.R. (1972). "Universals in color naming and memory". Journal of Experimental Psychology, 93: $10-20$.

11. JICA (2002). Country Profile on Disability (Kingdom of Thailand). Retrieved October 1, 2007 from siteresources.worldbank.org/DISABILITY/Resources/Regions/East-Asia-Pacific/JICA_Thailand.1.pdf

12. Kaiser, P.K. \& R.M., Boynton (1996). Human Color Vision. Washington, D.C.: Optical Society of America.

13. Keysar, B., et al. (2000). “Conventional language: How metaphorical is it?” Journal of Memory and Language, 43: 576-593.

14. Lucy, J.A. (1992). Language and Diversity of Thought: a Reformulation of the Linguistic Relativity Hypothesis. Cambridge: Cambridge University Press.

15. McNeill, N.B. (1972). "Colour and Colour Terminology". Journal of Linguistics, 8: 21-33.

16. Ozgen, E. \& I.R.L. Davies (2002). Acquisition of Categorical Color Perception: A Perceptual Learning Approach to the Linguistic Relativity Hypothesis". Journal of ExperimentalPsychology: General, 131: 477-493.

17. Pilling, M., et al. (2003). "Is Color Categorical Perception Really Perceptual?" Memory and Cognition, 31: 538-551.

18. Pitchford, N.J. \& K.T. Mullen (2001). "Conceptualization of Perceptual Attributes: A Special Case for Color?” Journal of Experimental Child Psychology, 80: 289-314.

19. Quinn, P.C. \& P.D. Eimas (1997). “A Re-examination of the Perceptual-to-conceptual Shift in Mental Representations". Review of General Psychology, 1: 271-287. 
20. Rice, M. (1980). Cognition to Language: Categories, Word Meanings and Training. Baltimore: University Park Press.

21. Roberson, D. et al (2004). "The Development of Color Categories in Two Languages: A Longitudinal Study". Journal of Experimental Psychology: General, 133: 554-571.

22. Roberson, D. et al. (2005). "Color Categories: Evidence for the Cultural Relativity Hypothesis". Cognitive Psychology, 50: 378-411.

23. Sandhoffer, C.M. \& L.B. Smith. (1999). "Learning Color Words Involves a System of Mappings". Developmental Psychology, 35: 568-679.

\section{$\underline{\text { NOTES }}$}

